Against such criteria, the presentation of preliminary data from a search for the genetic roots of homosexuality, at a meeting of the American Society of Human Genetics in Baltimore, Maryland, earlier this month, was a success. So why does it feel as if something went wrong?

In a ten-minute talk at the meeting, lead researcher Tuck Ngun described how his team scanned the DNA of 37 pairs of identical twins for chemical, or epigenetic, tags. They found a handful of similarities between many of the gay twins that were not present in their straight brothers.

Epigenetic tags, which often regulate gene expression, can be both inherited and affected by environmental factors, as seems to be the case for homosexuality itself. The findings were preliminary, but the idea that epigenetics is involved in sexual orientation is certainly plausible, and the researchers hoped that their findings would stimulate future research. Most labs shy away from studying homosexuality because funders are reluctant to wade into the topic and because of the well-founded worry that findings will be used in the misguided search for a 'cure'.

A flurry of press coverage ensued. Although some of the stories noted the study's small sample size and need for replication - limitations that the researchers readily acknowledged - others were somewhat less than circumspect. 'Have They Found the Gay Gene? Breakthrough in the US', screamed the front page of one newspaper.

Responding to the press coverage, many commentators took aim at the science - or at least what science was available in the 368-word conference abstract. The statistical analyses that the authors used are controversial, and there is a legitimate debate to be had. But short on hard information, the criticism turned into attack.
A few critics went so far as to argue that the authors should not have presented such preliminary work at the meeting. And at least one suggested that the authors could have provided preprints of their study when presenting it. These arguments seem to misunderstand the traditional, and still useful and relevant, role of such gatherings. Studies
"Meetings are an important testing ground for early research." with small sample sizes and controversial methods are presented at conferences all the time, and many scientists already fear being scooped when they present even a bit of their data.

It is unlikely that most newspapers seek science stories by meticulously scanning the abstract lists for foreign scientific conferences. It is much more likely that the wide coverage afforded to the epigenetics study arose because the story was presented to news desks in a press release from the conference organizers - and this is where there are lessons to learn.

The press release, which was not seen or approved by all the scientists involved, was titled 'Epigenetic Algorithm Accurately Predicts Male Sexual Orientation'. It certainly added to the potential for the study to be misinterpreted. The organizers have pledged to reconsider how they select which conference talks to highlight before a meeting, and how press releases are approved.

The genetics of homosexuality is a subject that will always find media coverage, partly because of the societal interest in the topic. Neither the scientists nor the conference organizers can be held responsible for how some in the media chose to write about the study. But both could have done more to get the right message across.

\section{Pick and mix}

\section{Food regulators are right to place new forms of data on the safety menu.}

$\mathrm{I}$ talian chocolate, Bangladeshi samosas, Chilean cornbread flans, Turkmenistani beef chapattis - the aromas of the world's traditional foods mingle seductively along the mile of pavilions at Expo Milano 2015, this year's world fair, dedicated to food. All delicious, but are they all safe? Will future foods be safe? Who is to judge - and on what evidence?

In Europe, the European Food Safety Authority (EFSA) decides whether a new food can be marketed, and its job (like that of all similar regulatory agencies around the world) is getting tougher. Technological advances are creating ever more novel foods.

The same technologies, along with the Internet and databases, have created more sources of information that may have a bearing on safety assessment: terabytes of molecular information from genomic or proteomic analyses, for example, or more-qualitative data generated through crowdsourcing.

Public trust in EFSA's decisions is patchy and, until now, the agency has been slow to engage with the problems and solutions that these technologies offer. But at a three-day conference in Milan - attached to the Expo, and concluding on 16 October, World Food Day - EFSA announced a new commitment to take on the modern challenges. As it does so, it can start to repair its rather undeserved reputation for non-transparency.

Created in 2002 and based in Parma, Italy, the agency is probably best known as the independent scientific advisory agency to the European Union, whose independent scientific advice on the safety of genetically modified (GM) cereals has been serially rejected by many EU member states.

In most cases, EFSA's science-based recommendations on the safety of new food products are accepted politically without too many questions. But the GM saga has encouraged a public distrust in its official scientific expertise. The scientific experts commissioned by EFSA over the years to analyse data on whether GM technologies or products are risky to health or the environment have seen their recommendations challenged time and again by protest groups that claim to have new data on dangers. As a one-off exception to the single-market rule, EU member states can decide on an individual basis whether they want to allow cultivation of a particular crop. Nineteen have registered their decisions to opt out, despite EFSA's seal of safety.

EFSA does a good job of risk assessment and is reasonably transparent - but to stop distrust from seeping into all areas of its work it needs to do more. Risk assessment is a complicated science to convey to the public and is becoming even more complex with every new potential source of information. EFSA must be transparent about the exact data that it uses to make individual judgements and about the methods it uses to determine the degree of uncertainty around those judgements. It must also find ways to transparently assign appropriate weight to different data types that have been collected with varying degrees of scientific rigour.

The agency is on the case. This year, it carried out a public consultation on the communication of uncertainties, and it is rolling out a toolbox of methods to be systematically tested over the next year. Such methods may address, for example, how to weigh up evidence generated from computer modelling, from animal data generated in labs or from data gathered over social media - or how to assess whether a particular change observed in an organism is biologically relevant.

By definition, risk assessment will never be able to deliver simple answers. And concerned citizens, rightly, will never place blind trust in scientific expertise. That is why transparency about both data sources and analysis methods is so important. Different people may $\rightarrow$ NATURE.COM To comment online, click on Editorials at: go.nature.com/xhunqv even interpret the same complex data set differently. Citizens just need to be given a clear picture of how a risk assessor has interpreted data - so that they can challenge or accept the final decision of the risk manager. 